\title{
CORRIGENDUM
}

doi:10.1038/nature08886

\section{Homotypic fusion of ER membranes requires the dynamin-like GTPase Atlastin}

Genny Orso, Diana Pendin, Song Liu, Jessica Tosetto, Tyler J. Moss, Joseph E. Faust, Massimo Micaroni, Anastasia Egorova,

Andrea Martinuzzi, James A. McNew \& Andrea Daga

\section{Nature 460, 978-983 (2009)}

In Figure $5 \mathrm{i}$ of this Article, the GTPase activity data contains a calculation error that occurred during the conversion of 2-amino-6mercapto-7-methylpurine absorbance to $\mu \mathrm{M}$ phosphate. As a result, the activity is over stated. The corrected Figure $5 \mathrm{i}$ with the appropriate $y$ axis is shown below. This change does not affect any of the conclusions of the work.

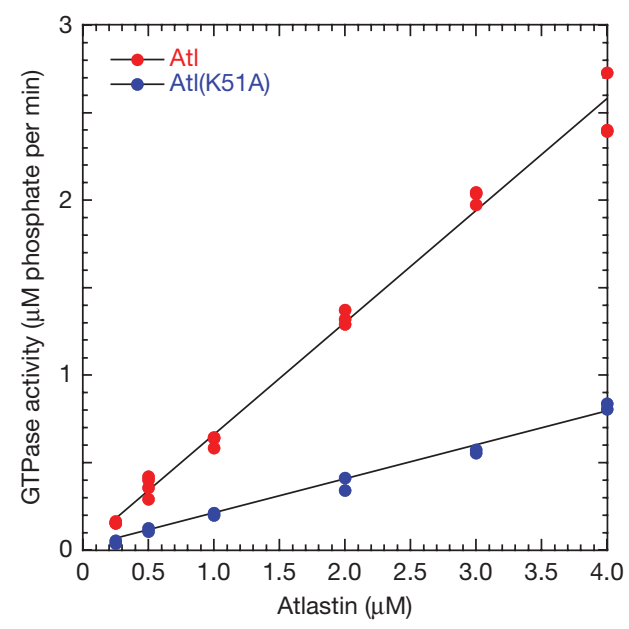

